\title{
The outcome of laparoscopic management of adnexal pathology complicating pregnancies
}

\section{Nagendra Prasad $^{1 *}$, Sarojamma Chunchiah ${ }^{1}$, R. Nagarathnamma ${ }^{1}$, Nirmala Chandrashekar ${ }^{1}$, Nirupama Y. Shivananjappa ${ }^{2}$, Sherin A. Thampan ${ }^{1}$}

\author{
${ }^{1}$ Department of Obstetrics and Gynecology, Rajarajeswari Medical College and Hospital, Anchepalya, Bangalore, \\ India \\ ${ }^{2}$ Department of Obstetrics and Gynecology, Shanbag Hostital, Bangalore, India
}

Received: 26 June 2016

Accepted: 08 July 2016

\section{*Correspondence:}

Dr. Nagendra prasad,

E-mail: drnnprasad@yahoo.com

Copyright: (c) the author(s), publisher and licensee Medip Academy. This is an open-access article distributed under the terms of the Creative Commons Attribution Non-Commercial License, which permits unrestricted non-commercial use, distribution, and reproduction in any medium, provided the original work is properly cited.

\begin{abstract}
Background: Adnexal pathology found during pregnancy is relatively common and the reported incidences are population and investigation dependent. The most frequent types of adnexal masses are corpus luteum cysts, endometriomas, benign cystadenomas and mature cystic teratomas. The objective was to study the feasibility of laparoscopic management of adnexal pathology in pregnancy, maternal complications and fatal outcome. We have reported 25 cases of adnexal pathology complicating pregnancy, managed successfully laparoscopically with no maternal and fetal complications.

Methods: The study is based on the outcome of laparoscopic management of adnexal pathology in 25 pregnant women over period of eight years. Laparoscopy was done using three port technique, $10 \mathrm{~mm}$ umbilical or supra umbilical port for optics and two lateral ports for instrumentation. Cystectomy was the most common procedure.

Results: There was no intra or post-operative complication observed in the study. Successful obstetric outcome in all the patients with no complications was observed.

Conclusions: Laparoscopy is preferred for exploration and treatment of adnexal masses especially between 14 to 25 weeks of gestation.
\end{abstract}

Keywords: Adnexal pathology, Pregnancy, Laparoscopy, Heterotropic pregnancy

\section{INTRODUCTION}

Adnexal pathology found during pregnancy is relatively common and the reported incidences are population and investigation dependent. ${ }^{1}$ The most frequent types of adnexal masses are corpus luteum cysts, endometriomas, benign cystadenomas and mature cystic teratomas. ${ }^{2}$ Heterotropic pregnancy is on the rise with increased use of IVF in management of infertility. ${ }^{3}$ Most ovarian masses are asymptomatic in pregnant women. Some cause pressure or chronic pain and acute abdominal pain due to torsion, rupture or haemorrhage. Complications of any ovarian mass are torsion and haemorrhage. If torsion is suspected, laparoscopy or laparotomy is warranted. ${ }^{4} \mathrm{~A}$ cystic benign appearing mass that is less than $5 \mathrm{~cm}$ needs no intervention, tumours between $5 \mathrm{~cm}$ to $10 \mathrm{~cm}$ careful sonographical evaluation is needed, and for cysts more than $10 \mathrm{~cm}$ surgical removal is reasonable due to risk of malignancy, torsion or labour obstruction.

Use of laparoscopy in pregnancy is reported as early as 1980. ${ }^{1}$ The most common surgeries performed during pregnancy are cholecystectomy, appendecectomy and removal of adnexal mass. ${ }^{2}$ The objective of this study was to study the feasibility of laparoscopic management of adnexal pathology in pregnancy, maternal complications and fatal outcome. 25 cases of adnexal pathology complicating pregnancy, managed successfully 
laparoscopically with no maternal and fetal complications were reported.

\section{METHODS}

Twenty five laparoscopic surgeries were performed from the year 2008-2015, for adnexal pathology with pregnancy. The common presentation was incidental finding of a tumour in early pregnancy scan. Few patients presented with pain abdomen and one patient with heterotropic pregnancy with internal bleeding and shock.

Laparoscopy was done using three port technique, $10 \mathrm{~mm}$ umbilical or supra umbilical port for optics and two lateral ports for instrumentation. Pneumoperitoneum was created using verres needle, through umbilicus or palmers' point as the situation demanded. After introduction of optic port through the umbilicus or supraumblically, with safety trochar, taking care not to injure gravid uterus, lateral ports were introduced under vision.

Cystectomy was the most common procedure. The two cases of heterotropic pregnancy were managed with salphingectomy. There were four cases of torsion ovarythree were hyper stimulated ovaries managed by detorsion and aspiration and one with gangrenous changes underwent salphingo-oopherectomy.

Cystectomy was established using hydro dissection, sharp dissection with scissors and graspers with traction and counter traction. Bipolar energy was used wherever cautery is necessary. Utmost care was taken not to touch the gravid uterus.

\section{RESULTS}

The mean age of patients in the study group was 24 years (19-32). Table 1 shows the gestational age at which the procedure was performed. Two patients below eight weeks of gestation one had ruptured heterotropic pregnancy and other had torsion of hyper stimulated ovary with twin gestation.

Table 1: Gestational age wise distribution of cases.

\begin{tabular}{|ll|}
\hline Gestational age & Number of cases \\
\hline$>8$ weeks & 2 \\
\hline 8 -11 weeks 6 days & 7 \\
\hline $12-15$ weeks 6 days & 13 \\
\hline $16-24$ weeks & 3 \\
\hline Total & 25 \\
\hline
\end{tabular}

The most common diagnosis was functional cyst, four cases of corpus luteal cysts were seen. Cystadenomas and dermoids were common in second trimester (Table 2). Cystectomy was the most common procedure.
Table 2: Pathological classification of adnexal pathology.

\begin{tabular}{|ll|}
\hline Type of adnexal pathology & Number of cases \\
\hline Corpus luteal cyst & 4 \\
\hline Dermoid & 3 \\
\hline Functional cyst & 6 \\
\hline Serous cystadenoma & 5 \\
\hline Para ovarian cyst & 4 \\
\hline Endometrioma & 2 \\
\hline Heterotropic pregnancy & 2 \\
\hline Total & 25 \\
\hline
\end{tabular}

There was no intra or post-operative complication observed in the study. All the pregnancies were followed to term or delivery. Two pregnancies were twins delivered at 34 and 36 weeks respectively. There were two cases of late preterm deliveries in the study. All the fetii were normal at delivery with no remarkable anomalies.

\section{DISCUSSION}

With routine use of ultrasound in early pregnancy, asymptomatic, incidental adnexal tumours have been detected in 1:80 cases. ${ }^{1}$ With advent of newer equipments and improved understanding of feto-maternal physiology and better monitoring intra-operatively, laparoscopy is more commonly used during pregnancy. ${ }^{2}$ Around $50 \%$ of cases in present study were in the gestational age group of 12-16 weeks. Need for postoperative analgesics are reduced after laparoscopy in comparison with laparotomy. ${ }^{4}$ The risk of paralytic ileus, the incidence of thromboembolic complications, rate of infection are less with laparoscopy. There were no significant major or minor complications in this study.

Preferable time for intervention will be around 14 weeks of gestation as organogenesis is complete and some tumours may resolve spontaneously. ${ }^{5}$ Technically it is difficult to do laparoscopy beyond 24 weeks of pregnancy and also risk of preterm labour increases. ${ }^{6}$ Due care should be taken while creating pnueperitoneum to avoid uterine perforation. As the pregnancy advances supra umbilical or palmer's point can be used. $10 \mathrm{~mm}$ safety tip trochar for primary port was used to further minimise the chances of uterine injury.

Carbon dioxide is the gas of choice, due to rapid absorption, high solubility and rapid clearance from the body in the alveoli and non-explosive nature when energy source is used. ${ }^{7}$ The risk of hypercarbia and respiratory acidosis can be minimised by keeping the intra abdominal pressure low and shortening of operative time. ${ }^{8}$ All the procedures were accomplished with an intrauterine pressure of $10 \mathrm{~mm}$ of hg.

Regarding the fetal outcome, concern is the effect of increased intra-abdominal pressure on fetal vascularity. 
There are no data showing detrimental effects to human fetuses from $\mathrm{CO} 2$ pneumoperitoneum. ${ }^{9}$ Additional potential danger is the risk of fetal exposure to intraabdominal smoke, generated by electrosurgery. A recent study failed to detect increased levels of carboxy hemoglobin in woman who underwent prolonged laparoscopic procedures when smoke was evacuated simultaneously. ${ }^{10}$ No fetal complications were found in the study.

\section{CONCLUSION}

Laparoscopy is a safe option in management of adnexal pathology in pregnancy. It is better to time the elective procedure around 14 weeks in order to allow spontaneous resolution of functional/corpus luteal cysts and also avoid the period of organogenesis. A trained and experienced laparoscopic surgeon can perform laparoscopic procedure in the time duration similar to laparotomy. No specific adverse fetal events are reported in the literature attributing it to laparoscopy. However these observations need to be supported by prospective randomized controlled studies.

Funding: No funding sources

Conflict of interest: None declared

Ethical approval: Not required

\section{REFERENCES}

1. Hess LW, Peaceman A, O’Brien WF, Winkel CA, Cruikshank DP, Morrison JC. Adnexal mass occurring with intrauterine pregnancy: report of fiftyfour patients requiring laparotomy for definitive management. Am J Obstet Gynecol. 1988;158:102934.
2. Nezhat CR, Nezhat FR, Luciano AA, Siegler AM, Metzger DA, Nezhat $\mathrm{CH}$, eds. Operative Gynecologic Laparoscopy: Principles and Techniques. New York: McGraw-Hill;1995:507.

3. Dimitry ES, Subak SR, Mills M, Margara R, Winston R. Nine cases of heterotopic pregnancies in 4 years of in-vitro fertilization. Fertil Steril. 1990;53(1):107-10.

4. David S, Yuval Y, Daniel SS, Mordechai G, Shlomo $\mathrm{M}$, et al. Laparotomy vs Laparoscopy in the management of adnexal masses during pregnancy. Fertil Steril. 1999;71(5):955-60.

5. Platek DN, Henderson CE, Goldberg GL, Anderson CT, Boynton CJ, Peoples JB, et al. The management of a persistent adnexal mass in pregnancy. Am J Obstet Gynecol.1995;173:1236-40.

6. Mckellar DP, Anderson CT, Boynton CJ, Peoples JB. Cholecystectomy during pregnancy without fetal loss. Surg Gynecol Obstet. 1992;174:465-8.

7. Alexander GD, Brown EM. Physiologic alterations during pelvic laparoscopy. Am J Obstet Gynecol. 1969;105:1078-81.

8. Motew M, Ivankovich AD, Bieniarz J, Albrecht RF, Zahed B, Scommegna A. Cardiovascular effects and acid-base and blood gas changes during laparoscopy. Am J Obstet Gynecol. 1973;115:1002-12.

9. Fahim M, Rojansky N. Laproscopic surgery during pregnancy Obstet Gynecol. 2001;56:50-9.

10. Nezhat C, Sidman, Vernan HJ. The risk of carbon monoxide poisoining after prolonged laparoscopic surgery. Obstet Gynecol. 1996:85:771-4.

Cite this article as: Prasad N, Sarojamma C, Nagarathnamma R, Nirmala C, Nirupama YS, Thampan SA. The outcome of laproscopic management of adnexal pathology complicating pregnancies. Int J Reprod Contracept Obstet Gynecol 2016;5:2519-21. 